\title{
UVEÍTE RECORRENTE EQÜINA (CEGUEIRA DA LUA)
}

\author{
EQUINE RECURRENT UVEITIS (MOON BLINDNESS)
}

\author{
Antonio Cezar de Oliveira Dearo ${ }^{1}$ Mírian Siliane Batista de Souza ${ }^{1}$
}

\section{- REVISÃO BIBLIOGRÁFICA -}

\section{RESUMO}

\begin{abstract}
Conhecida como uma das mais importantes causas de cegueira nos eqüinos, a uveíte recorrente eqüina (URE) caracteriza-se por repetidos episódios de inflamação ocular interrompidos por períodos variáveis de quiescência clínica. Muito embora diversos fatores tenham sido relacionados à ocorrência de URE, acredita-se que a doença se desenvolva pela ação de agentes como Leptospira interrogans e a microfilária do nematóide Onchocerca cervicalis, em conseqüência de reações imunomediadas intra-oculares. Os sinais clínicos da fase aguda, como epífora, blefarospasmo, fotofobia, hiperemia conjuntival, miose, opacidade corneana e do humor aquoso, hifema e hipópio, podem ser encontrados em diferentes graus. Os sinais da fase crônica podem incluir sinéquias, alterações na forma e pigmentação normais da íris, luxação ou subluxação do cristalino e catarata, entre outros. $O$ tratamento tem como principais objetivos a redução da inflamação uveal, a preservação da motilidade da pupila e a prevenção de seqüelas que levem à cegueira, e consiste, fundamentalmente, no uso de drogas antiinflamatórias e midriáticos e cicloplégicos. O prognóstico, quanto à conservação da visão, está na dependência da intensidade e freqüência dos episódios recorrentes e do sucesso do tratamento.
\end{abstract}

Palavras-chave: uveíte, iridociclite, oftalmia, cegueira, eqüino.

\section{SUMMARY}

Known as the leading cause of blindness in horses, equine recurrent uveitis (ERU) is characterized by several attacks of intra-ocular inflammation alternated with variable periods of clinical quiescence. Although many factors have been related to ERU it seems that Leptospira interrogans and the microfilaria of Onchocerca cervicalis play an important role in the pathogenesis through an immune-mediated mechanism. Clinical findings in the acute phase include variable degrees of epifora, blepharospasm, photophobia, conjunctival hyperemia, miosis, corneal opacity, aqueous flare, hyphema, and hypopyon. Clinical findings consistent with chronic phase include synechiae, changes in shape and pigmentation of the lens, cataract and lens luxation or subluxation. The principal goals of treatment are reduction of uveal inflammation, preservation of pupil's motility, and prevention of blindness. Therapy consists mainly of antiinflamatory and mydriatics/cycloplegic drugs. The prognosis for preservation of vision varies with severity and frequency of recurrencies, and the success of the treatment.

Key words: uveitis, iridocyclitis, ophtalmia, blindness, equine.

\section{INTRODUÇÃO}

O processo inflamatório das estruturas que compõem a úvea ou trato uveal (íris, corpo ciliar e coróide) apresenta-se como uma das mais importantes causas de cegueira nos eqüinos (REBHUN,1979;1991). Também conhecida como iridociclite recorrente (LAVACH, 1990), oftalmite recorrente, oftalmia periódica $(\mathrm{BEECH}, 1987)$ ou fluxo periódico (JONES, 1942), a uveíte recorrente eqüina (URE) caracteriza-se fundamentalmente por repetidos episódios de inflamação ocular interrompidos por períodos variáveis de quiescência clínica (DAVIDSON, 1991;1992). Antigamente, relacionavam-se os episódios da doença às fases da lua, originando-se daí o nome "cegueira da lua" (SEVERIN, 1976; BEECH, 1987).

Reconhecida há séculos entre as populações de eqüinos de todo o mundo, a uveíte recorrente não tem predileção por idade, sexo ou raça, podendo acometer um ou ambos os olhos (JONES, 1942; SLATTER, 1990). Simultaneamente, a cada

\footnotetext{
${ }^{1}$ Médico Veterinário, professor assistente do Departamento de Clínicas Veterinárias do Centro de Ciências Agrárias da Universidade Estadual de Londrina, CP 6001, 86051-990, Londrina, PR, Brasil. E-mail: dearo@ sercomtel.com.br
} 
episódio de recorrência ocorre um agravamento progressivo do processo inflamatório uveal, aumentando a ocorrência de seqüelas responsáveis pelo comprometimento da visão (GLAZE, 1990; DAVIDSON, 1992). Para tanto, o diagnóstico precoce realizado através de um exame oftálmico completo e minucioso, associado a uma terapêutica agressiva e disciplinada, seguramente reduzirão em muito as possibilidades de perda total ou parcial da visão.

\section{DESENVOLVIMENTO}

Ao longo de décadas, inúmeros fatores foram relacionados à ocorrência de URE, como pode ser verificado pelas investigações de JONES (1940;1949), JONES et al. (1945), e LAVACH (1990). Embora muitos desses fatores não mais sejam considerados como potenciais causadores de uveíte recorrente no cavalo, muitos aspectos relacionados aos possíveis agentes propostos ainda são rodeados de muitas incertezas (STANNARD \& CELLO, 1975). Acredita-se atualmente que a URE se desenvolva em conseqüência de reações imunomediadas intra-oculares deflagradas em resposta à ação de diversos agentes, entre os quais a Leptospira interrogans e a microfilária do nematóide Onchocerca cervicalis figurem entre os principais (YAGER et al., 1950; ROBERTS, 1963). Entretanto, enfermidades como adenite eqüina ou "garrotilho" (ROBERTS, 1971), brucelose, toxoplasmose, viroses causadas por influenzavírus e adenovírus, trauma ocular direto ou perfurante e outros fatores podem também estar relacionados (KERN, 1987; GLAZE, 1990).

Ainda que a URE seja conhecida como enfermidade desde o século IV $\mathrm{AD}$, os fenômenos fisiopatológicos inerentes ao seu desenvolvimento permanecem obscuros (HINES, 1984). Observações clínicas e experimentais, como a natureza recidivante da doença em alguns indivíduos, a presença de infiltrado linfocítico na íris e corpo ciliar em decorrência da inflamação uveal e a resposta da doença à terapia corticosteróide, levam a crer que reações imunomediadas desempenham importante papel na fisiopatologia da URE (MAIR \& CRISPIN, 1989). Diversos mecanismos imunopatogênicos têm sido propostos para explicar não só o episódio inicial, como também as recidivas. MAIR \& CRISPIN (1989) acreditam que as reações de hipersensibilidade, agudas ou crônicas, responsáveis pela inflamação uveal possam ser mediadas por barreiras anatômicas intra-oculares que prejudicariam a eliminação do antígeno pelos mecanismos imunogênicos, perpetuando, dessa forma, o estímulo antigênico ou alergênico no interior do trato uveal. De forma aná- loga, a barreira hemato-aquosa poderia impedir o desenvolvimento de uma "tolerância imunológica" aos próprios antígenos do olho que, quando expostos em decorrência de lesões oculares, estimulariam o desencadeamento de reações auto-imunes associadas a reações de hipersensibilidade a antígenos extrínsecos. De acordo com as observações de HINES (1984), MAIR \& CRISPIN (1989) e SLATTER (1990), os episódios recidivantes poderiam ser explicados pela retenção de linfócitos de memória sensibilizados no interior do trato uveal que, mesmo após a melhora clínica do episódio inicial, serviriam como base para o início de novos episódios de inflamação (resposta anamnésica). Outra possibilidade recairia sobre o agente antigênico que, permanecendo no local em estado latente após a inflamação inicial, desencadearia novo episódio inflamatório quando determinadas condições, ainda desconhecidas, favorecessem sua reativação (O'CONNOR, 1983; HINES, 1984). Esse mecanismo poderia explicar os quadros de uveíte provocados pela Leptospira nos quais os episódios recidivantes podem ser observados 1 a 2 anos após Leptospirose sistêmica (SLATTER, 1990).

Outras reações imunogênicas, como hipersensibilidade imediata ou do tipo I mediada por IgE e mastócitos, hipersensibilidade citotóxica anticorpo dependente ou do tipo II, hipersensibilidade mediada pela deposição de imunocomplexos ou do tipo III e hipersensibilidade mediada por células ou do tipo IV, também conhecida como hipersensibilidade retardada, têm sido propostas como possíveis mecanismos responsáveis pelas alterações intraoculares observadas na URE (HINES, 1984). Evidências clínicas e experimentais sugerem que fenômenos auto-imunes possam estar fortemente relacionados aos episódios de uveíte (HINES, 1984). Inoculações de determinadas proteínas próprias da retina, uma delas conhecida como antígeno S, têm induzido ao desenvolvimento de uveítes alérgicas em várias espécies de animais de laboratório. Entretanto, as observações registradas por MAXWELL et al. (1991) não permitiram estabelecer relações entre o antígeno $\mathrm{S}$ e a ocorrência de uveíte recorrente em equiinos.

Os sinais clínicos observados durante o exame oftálmico são variáveis de acordo com a intensidade e duração da uveíte (REBHUN, 1979). Cavalos com episódios agudos, iniciais ou recorrentes, podem mostrar sinais clínicos semelhantes a outras desordens oculares, tais como úlcera de córnea e blefarite. Sinais como epífora, blefarospasmo, fotofobia, hiperemia conjuntival, opacidade corneana e do humor aquoso, hifema, hipópio e miose ocorrem em maior ou menor grau de intensidade (KERN, 1987; LAVACH, 1990). 
SLATTER (1990) também relata a ocorrência de outras alterações, como vitiligo nas regiões do escroto, canto lateral do olho e limbo conjuntival lateral, dermatite focal nas regiões da cabeça, tórax ventral e pescoço, hiperemia e quemose da conjuntiva perilimbal temporal e opacidade corneana focal no limbo lateral em animais portadores de uveíte relacionada à oncocercose.

A proeminência ou projeção dos vasos circunciliares (vasos sangüíneos profundos localizados na transição esclero-corneana ou limbo) é um achado consistente na uveíte (KERN, 1987; GLAZE, 1990). A opacidade corneana freqüentemente presente pode ser devida, basicamente, a três processos: edema do estroma, neovascularização ou ulcerações da córnea (KERN, 1987). O edema do estroma é causado por disfunção do endotélio da córnea e por alteração na permeabilidade dos vasos localizados no limbo. Se o endotélio for severamente danificado, a opacidade corneana pode tornar-se permanente (REBHUN, 1979; KERN, 1987).

Diferentes graus de opacificação da câmara anterior, os quais podem ser confundidos com opacificação da córnea, são observados em casos de URE. A opacidade resultante da passagem de proteínas, principalmente fibrina, e células inflamatórias para o interior da câmara anterior, em virtude do aumento de permeabilidade dos vasos da íris e do corpo ciliar, é denominada de hipópio (REBHUN, 1979; KERN, 1987). A presença de sangue na câmara anterior ou hifema também pode ser observada, principalmente nos casos de uveíte traumática (MILLER \& WHITLEY, 1987). Alterações na forma e pigmentação normais da íris podem ser identificadas como resultado de edema e infiltração celular (REBHUN, 1979; KERN, 1987).

O espasmo do músculo constritor da íris, resultando em miose, é um dos principais responsáveis pela dor no interior do olho. A menos que existam aderências impedindo a movimentação da íris, o olho afetado pela uveíte sempre apresentará miose em relação ao olho sadio. Quando ambos os olhos estão acometidos, as pupilas apresentam-se diminuídas em relação àquelas de cavalos normais quando examinados nas mesmas condições de luz (REBHUN, 1979).

Ultrapassado o episódio agudo inicial ou recidivante, o qual pode durar vários dias, sobrevêm a fase quiescente, na qual os animais não apresentam sinais clínicos de inflamação ocular, entretanto, evidências histológicas comprovam que, mesmo durante essa fase, há continuidade do processo inflamatório uveal, porém em menor intensidade (ROBERTS, 1962,1963; HINES, 1984).
Em casos recidivantes ou crônicos, alterações como sinéquias (anterior ou posterior), atrofia e despigmentação da íris e catarata, abrangendo grandes extensões da lente, podem ser observadas. Aderências extensas da íris ao cristalino (sinéquia posterior) podem resultar em íris bombé (abaulamento da íris pelo acúmulo de humor aquoso), glaucoma e catarata focal nos sítios de aderência (REBHUN, 1979; GLAZE, 1990). LAVACH (1990) e SPIESS (1997) referem que a URE é considerada como a principal causa de catarata em equiinos.

Outras alterações observadas, principalmente na fase crônica da doença, podem incluir a presença de pigmentos na cápsula anterior do cristalino, degeneração, luxação ou subluxação do cristalino e degeneração dos ligamentos zonulares (zônula) e do humor vítreo, sendo essa última traduzida pela sua liquefação (SCHLOTTHAUER, 1933; DAVIDSON, 1992).

A luxação do cristalino pode ocorrer no sentido anterior ou posterior e ser devido à inflamação, cicatrização e degeneração hialina do corpo ciliar, processos ciliares e dos ligamentos zonulares. $\mathrm{Na}$ luxação anterior, o cristalino se desloca para a câmara anterior, podendo causar edema de córnea pelas lesões provocadas no endotélio corneano. Adicionalmente, a luxação anterior pode causar glaucoma secundário pela diminuição do ângulo de drenagem do humor aquoso (REBHUN, 1991).

Alterações da retina, que seguem ou acompanham a uveíte, incluem: corioretinite, focos de hiperpigmentação e despigmentação peripapilar (butterfly lesions) e descolamento da retina causada por exsudação coroidal ou pela formação de bandas fibrosas no interior do humor vítreo, constituídas por fibrina e debris celulares que se aderem à retina e exercem tração sobre a mesma. Ao exame, aparecem como estrias lineares esbranquiçadas ou acinzentadas que se estendem através do humor vítreo em direção à retina (ROBERTS, 1962; REBHUN, 1979; KERN, 1987).

Usualmente, a pressão intra-ocular (PIO) está diminuída em casos de uveíte, pelo decréscimo na produção de humor aquoso (GLAZE, 1990). A palpação do olho afetado, comparando-se com o olho contralateral, pode sugerir se há aumento ou diminuição da PIO, todavia, não se deve considerála como um dado confiável (REBHUN, 1979; KERN, 1987; DAVIDSON, 1992). A hipotonia pode persistir nas fases quiescentes da doença predispondo à retração degenerativa de todo globo ocular conhecida como Phthisis bulbi (JONES, 1942; SPIESS, 1997). 
A ausência de sinais clínicos de inflamação ocular aguda, na fase quiescente, permite que os sinais de uveíte crônica sejam melhor identificados nessa fase. Dessa forma, a identificação de alterações de caráter crônico, durante o exame oftálmico de animais portadores de outras desordens oculares, deve sempre levantar a suspeita de uveíte prévia ou quiescente (SLATTER, 1990) (Figura 1).

O diagnóstico é feito fundamentalmente através dos achados do exame clínico e pela história de episódios recorrentes crônicos de doença ocular (GLAZE, 1990). Um completo e cuidadoso exame clínico do globo ocular deve ser conduzido em ambos os olhos, mesmo que o comprometimento seja unilateral. Entretanto, isso pode não ser conseguido em muitos animais portadores de forte blefarospasmo ou mesmo naqueles onde, ao menor toque, tornam-se intolerantes à manipulação, tendo em vista o intenso desconforto ocular. Nessas circunstâncias, a tranquilização e aquinesia necessárias para um completo exame oftálmico podem ser conseguidas mediante o uso de sedativos parenterais e pelo bloqueio anestésico do nervo aurículo palpebral, respectivamente.

Muitas alterações do olho externo e anexos, assim como lesões intra-oculares anteriores ao humor vítreo, podem ser identificadas e caracterizadas pela inspeção com uma fonte de luz externa (Ex: lanterna). O exame do fundo de olho, quando não impedido pelos sinais clínicos da uveíte, deve ser realizado com um oftalmoscópio. Sempre que possível, deve-se lançar mão do uso de midriáticos tópicos (Ex: tropicamida), permitindo assim uma melhor avaliação do cristalino, humor vítreo e fundo de olho. A verificação de lesões ulcerativas da córnea, através do uso tópico de fluoresceína, reveste-se de grande importância clínica, uma vez que elas contraindicam o uso de antiinflamatórios esteróides (corticóides) tópicos entre as drogas de escolha para o tratamento da uveíte (REBHUN, 1979). Como auxílio diagnóstico, podem ser feitos testes de sorologia pareada para leptospirose, brucelose e toxoplasmose. A biópsia conjuntival (conjuntiva bulbar) pode identificar a presença da microfilária de Onchocerca cervicalis (KERN, 1987; LAVACH, 1990).
Como já referido anteriormente, os sinais de uveíte crônica são melhor observados durante a fase quiescente. Esse aspecto ressalta a importância da realização de exames periódicos durante a evolução da doença, não só para se avaliar a eficiência do tratamento, como também para se identificar alterações não definidas nos exames preliminares.

Para que o tratamento da uveíte no cavalo possa lograr êxito, deve-se ter em mente que a obstinação e a perseverança devem ser considerados, seja pelo veterinário responsável, seja pelo proprietário ou pessoa diretamente ligada ao tratamento. A avaliação clínica precipitada, com conseqüente inadequação terapêutica, a falta de assiduidade no tratamento ou, ainda, a descontinuidade precoce da terapia, certamente resultarão em insucessos de maior ou menor grau.

Considerando que, na maior parte dos casos de URE, não se consegue identificar o agente causal, o tratamento tem por objetivos principais a redução da inflamação uveal, a preservação do tamanho e motilidade da pupila, o alívio da dor e a prevenção da cegueira como seqüela (KERN, 1987; WHITLEY et al., 1993). Contudo, naqueles casos em que se consegue determinar o agente, a terapia específica deve ser instituída, juntamente com o tratamento sintomático.

A administração tópica de medicações oftálmicas em animais de temperamento rebelde e de difícil manejo, que apresentem intenso blefarospasmo, ou, ainda, naqueles onde a medicação deva ser aplicada diversas vezes ao dia, para que o tratamento tenha sucesso, é muito facilitada pelo uso de sistemas de lavagem subpalpebral ou nasolacrimal (GLAZE, 1987; DAVIDSON, 1991,1992). As pomadas oftálmicas muitas vezes são preferidas aos colírios por apresentarem um maior tempo de contato com o olho (REBHUN, 1991).

\section{Corticosteróides}

Os corticosteróides podem ser administrados pelas vias tópica, subconjuntival, parenteral ou por uma combinação dessas, de acordo com a severidade dos sinais clínicos. A supressão dos sinais, assim como o alívio da dor estão relacionados à via de administração empregada e à freqüência das aplicações. Dessa maneira, e para o tratamento dos casos brandos, o que é relativamente infreqüente, a aplicação tópica 3 a 4 vezes ao dia pode ser efetiva. Para casos moderados, a aplicação tópica freqüente, a cada 4 a 6 horas, combinada à injeção subconjuntival é a melhor escolha. Em casos de uveíte severa, o tratamento tópico intensivo a cada 2 horas, combinado à injeção subcon-
Figura 1 - Diferentes fases de evolução da uveíte recorrente eqüina. Redesenhado de SLATTER (1990). 
juntival e administração parenteral ou oral, pode ser necessário para controlar a inflamação. Em todas essas circunstâncias, o uso de drogas antiinflamatórias não esteróides (DAINEs), midriáticos e cicloplégicos também está indicado (KERN, 1987).

A eficácia no uso de corticosteróides tópicos é limitada pela frequiência com que são usados e pelo seu tempo de contato com o olho, que é relativamente curto (KERN, 1987). Muitos produtos podem ser usados com sucesso. O acetato de prednisolona se distingue pela sua excelente penetração intra-ocular e por isso deve ser a droga de escolha. Preparações de dexametasona também podem ser usadas com sucesso.

Uma via adjuvante ou alternativa para o uso de corticosteróides no tratamento da uveíte é a subconjuntival. ABRAMS \& BROOKS (1990) e WHITLEY et al.(1993) referem que a utilização de 10 a 40mg de acetato de metilprednisolona em 0,5 a $1 \mathrm{~m} \ell$, injetado abaixo da conjuntiva bulbar, confere bons resultados por uma a quatro semanas. Entretanto, BEECH (1987) e SLATTER (1990) referem a ocorrência de irritação local e formação de nódulos subconjuntivais após o uso de metilprednisolona. $\mathrm{O}$ acetato de prednisolona, na dose de 10 a $25 \mathrm{mg}$ em 0,5 a $1 \mathrm{~m} \ell$ de solução, pode ser administrado da mesma forma, mas por um menor tempo útil (24 a 48 horas). A triamcinolona ( 3 a $6 \mathrm{mg}$ em 0,5 a $1 \mathrm{~m} \ell$ de solução) (KERN, 1987) produz efeito intermediário de 3 a 7 dias, porém tem sido incriminada por causar laminite. ABRAMS \& BROOKS (1990) e WHITLEY et al. (1993), entretanto, recomendam uma dose maior para a triamcinolona de 20 a 40mg, podendo ser repetida dentro de 1 a 3 semanas ou de acordo com a evolução do quadro. WHITLEY $\boldsymbol{e t}$ al. (1993) também referem o uso de betametasona, na dose de $7,5 \mathrm{mg}$ em $0,5 \mathrm{~m} \ell$ de solução, podendo ser repetida dentro de 1 a 3 semanas ou de acordo com a evolução do quadro.

Cabe ressaltar, que a aplicação não só de corticóides, mas também de outras drogas pela via subconjuntival deve ser realizada injetando-se a solução sob a conjuntiva bulbar. Injeções na conjuntiva palpebral não conferem níveis terapêuticos adequados no interior do olho, uma vez que o fluxo sangüíneo palpebral remove a droga do local (REBHUN, 1991). DAVIDSON (1992) refere que o uso tópico associado de DAINEs (flurbiprofen $0,1 \%$ ) e corticóides pode ser bastante benéfico em casos de uveítes severas ou de difícil controle pelo efeito sinérgico estabelecido pela combinação das drogas.

O julgamento clínico e os achados dos exames seguintes determinarão a necessidade de nova aplicação subconjuntival. A aplicação sistêmi- ca de corticosteróides reserva-se aos casos de uveíte severa, nos quais nem a aplicação tópica ou subconjuntival foram capazes de promover alívio do processo. Em razão dos potenciais efeitos secundários dos corticóides sistêmicos, os quais incluem laminite, síndrome de cushing iatrogênica e imunossupressão (WHITLEY et al, 1993), o uso de antiinflamatórios não esteróides deve ser considerado em primeira instância. Se, mesmo assim, provarem ineficiência, a dexametasona na dose de 20mg IM duas vezes ao dia (KERN, 1987; REBHUN, 1991) ou a prednisolona na dose de 0,5 a $1 \mathrm{mg} / \mathrm{kg} / \mathrm{dia}$ (ABRAMS \& BROOKS, 1990) ou de 1 a $2 \mathrm{mg} / \mathrm{kg}$, via oral (WHITLEY et al., 1993), ambas durante 5 a 7 dias, podem ser utilizadas, reduzindo-se gradativamente a dose ao longo dos dias subseqüentes.

A duração do tratamento com corticosteróides tópicos deve ser prolongada por no mínimo 2 semanas após a melhora clínica, pois não só irá reduzir a inflamação subclínica do trato uveal como diminuirá a probabilidade de recidivas, notadamente aquelas que ocorrem nos primeiros 2 meses após a cessação da terapia de curto prazo (REBHUN, 1979;1991; WHITLEY et al., 1993).

Apesar de drogas dessa classe apresentarem efeitos positivos no tratamento da uveíte, por outro lado, podem causar efeitos colaterais indesejáveis como a supressão da epitelização corneana, através da potencialização da atividade da enzima colagenase, contra-indicando, portanto, seu uso em casos de úlceras de córnea (KERN, 1987). Na vigência de ulcerações corneanas, DAINEs, por via tópica e sistêmica, e midriáticos e cicloplégicos devem ser usados primeiramente (KERN, 1987; DAVIDSON, 1992).

Um grande inconveniente da maioria dos antiinflamatórios esteróides tópicos disponíveis atualmente no mercado é a inclusão de antibióticos em suas formulações. Em casos de uveíte não acompanhada por úlcera de córnea, a utilização de antibióticos pode levar não só ao estabelecimento de um meio adequado ao crescimento de fungos, como também à alteração da flora bacteriana normal da superfície corneana, sendo, nessas circunstâncias, contra-indicados (DAVIDSON, 1992).

\section{Drogas antiinflamatórias não esteróides (DAINEs)}

O processo inflamatório ocular está associado ao complexo metabolismo das prostaglandinas no interior do trato uveal. As drogas desse grupo, largamente empregadas na clínica eqüina e, aqui, em especial para o tratamento da uveíte, apresentam atividade antiprostaglandínica com notáveis resultados minimizando, dessa forma, os riscos potenciais 
causados pela terapia esteróide no manejo da uveíte. Três drogas antiprostaglandínicas são usualmente empregadas no tratamento da URE. A fenilbutazona, administrada por via oral ou intravenosa, na dose de 2,2 a $4,4 \mathrm{mg} / \mathrm{kg}$, a cada 12 horas, durante 5 a 7 dias, confere um bom efeito antiinflamatório e analgesia. Pode ser mais efetiva em casos moderados, assim como de forma profilática em baixas doses pela via oral para cavalos portadores de uveíte recorrente intratável.

O flunixim meglumine tem marcado efeito antiinflamatório, analgésico, antiespasmódico e antipirético. Essa droga é a de escolha para o tratamento de casos moderados a severos, podendo ser administrada por via oral, IM ou IV, 1 ou 2 vezes ao dia na dose de $1,1 \mathrm{mg} / \mathrm{kg}$, durante 5 a 7 dias (KERN, 1987; DAVIDSON, 1992).

Embora clinicamente menos potente que a fenilbutazona e o flunixim meglumine, o ácido acetil salicílico na dose de $15 \mathrm{mg} / \mathrm{kg}, 2$ vezes ao dia, VO (KERN, 1987) ou 30mg/kg 1 vez ao dia, VO (WHITLEY et al. 1993) tem sido usada com sucesso na profilaxia da uveíte recorrente crônica, após o episódio agudo ter sido tratado com outras drogas. Efeitos colaterais do uso de antiprostaglandínicos incluem ulcerações gastrentéricas e disfunção renal.

Drogas antiinflamatórias não esteróides de uso tópico como o flurbiprofen a $0,1 \%$ instilado, 3 a 6 vezes ao dia, devem ser empregadas em substituição aos corticóides nos casos de URE acompanhados de úlceras da córnea (ABRAMS \& BROOKS, 1990; DAVIDSON, 1992).

\section{Midriáticos e Cicloplégicos}

Além de prevenirem a formação de sinéquias, pela diminuição da superfície de contato entre a íris e o cristalino, determinada pela midríase, o efeito cicloplégico dessas drogas reduz o espasmo ciliar responsável, em grande parte, pela dor intraocular (ABRAMS \& BROOKS, 1990; DAVIDSON, 1992).

Esses efeitos podem ser conseguidos pelo uso de atropina na concentração de 1 ou $4 \%$, a cada 1 ou 2 horas até a pupila dilatar-se. Uma vez dilatada, a midríase poderá ser mantida com menor frequiência de aplicação, isto é, a cada 6 a 12 horas (GLAZE, 1990; DAVIDSON, 1992). Cavalos recebendo atropina oftálmica devem ser monitorados para possíveis episódios de desconforto abdominal (cólica) em razão de variados graus de estase intestinal. Ainda que tais episódios sejam incomums, é aconselhável que as aplicações se iniciem com a concentração mais baixa (1\%). Caso não haja resultado favorável dentro de 24 a 48 horas, recomendase o uso da droga na concentração de $4 \%$ apenas por 1 a 2 dias (DAVIDSON, 1992). A possibilidade da ocorrência de dor abdominal não deve impedir a utilização da atropina, pois a necessidade e os benefícios causados por sua ação superam, em muito, um possível risco (DAVIDSON, 1992). O trato uveal inflamado é marcadamente resistente aos efeitos da atropina. Se a midríase é pequena ou incompleta, o hidrocloridrato de fenilefrina a $10 \%$ pode ser administrado simultaneamente com a atropina sem apresentar, entretanto, efeito cicloplégico (KERN, 1987; DAVIDSON, 1992). A metilescopolaminafenilefrina pode substituir ambos. O único cuidado que se deve tomar com a fenilefrina é que sua aplicação não deve ser muito freqüente, pois pode provocar o aparecimento de úlceras de córnea (KERN, 1987; GLAZE, 1990). SPIESS (1997) refere que a injeção subconjuntival de 1 a $1,5 \mathrm{~m} \ell$ de uma formulação contendo epinefrina $(0,33 \mathrm{mg} / \mathrm{m} \ell)$, sulfato de atropina $(3,3 \mathrm{mg} / \mathrm{m} \ell)$ e cloreto de cocaína $(1,0 \mathrm{mg} / \mathrm{m} \ell)$ pode mostrar-se muito eficiente em casos onde há expressivo espasmo da musculatura ciliar.

A midríase pode persistir por mais de 4 semanas após a cessação das aplicações e os proprietários devem ser informados a esse respeito. Uma vez estabelecida a midríase, maiores quantidades de luz atingem o fundo de olho podendo causar sérias lesões na retina. Para tanto, deve-se manter o animal em local com pouca iluminação ou fazer uso de venda (REBHUN, 1979; BEECH, 1987).

\section{Antibióticos}

Uma das indicações para o uso de antibióticos em casos de uveíte se baseia na presença de úlcera de córnea. Na prática, como já referido anteriormente, muitos corticóides tópicos são acompanhados de antibióticos de amplo espectro como bacitracina-neomicina-polimixina $\mathrm{B}$, gentamicina $\mathrm{e}$ cloranfenicol. Ainda que os antibióticos contidos nessas formulações possam ser benéficos em casos de uveítes acompanhadas por úlceras de córnea, a presença do corticóide contra-indicaria seu uso. Portanto, somente formulações antibióticas não contendo esteróides devem ser utilizadas. Ulcerações superficiais podem ser tratadas pelo uso de soluções oftálmicas contendo antibióticos de amplo espectro, numa freqüência de 3 a 4 aplicações ao dia, ao passo que úlceras profundas complicadas por variados graus de ceratomalácea e neovascularização devem ser submetidas à colheita de material (swab) para cultivo e antibiograma (MOORE, 1992).

A indicação para a antibioticoterapia sistêmica se dá nos casos de uveíte septicêmica, principalmente em potros, e em casos de forte suspeita de infecção por Leptospira sp. Animais portadores de títulos para Leptospira devem ser considerados sus- 
peitos de abrigarem microorganismos viáveis e devem ser tratados com antibiótico específico (estreptomicina-penicilina) (KERN, 1987).

\section{OUTROS MÉTODOS DE TERAPIA}

\section{Microfilaricidas}

O papel da infecção provocada por larvas de Onchocerca cervicalis, em casos de uveíte aguda ou recorrente, ainda não está completamente elucidado (STANNARD \& CELLO, 1975). Até que se comprove a existência de uma relação concreta, a terapia larvicida deve ser considerada para cavalos portadores de uveíte, na qual a biópsia de pele ou conjuntiva mostrou a presença da microfilária. Entretanto, o tratamento não deve ser realizado durante os episódios ativos da doença, pois a morte da microfilária pode exacerbar o processo inflamatório. Por isso, o tratamento com microfilaricidas deve ser adiado até que o processo se torne quiescente (HINES, 1984; SLATTER, 1990). Duas drogas podem ser usadas: o citrato de dietil carbamazina pode ser administrado VO, na dose de $4 \mathrm{mg} / \mathrm{kg}$, 1 vez ao dia durante 21 dias ou a ivermectina na dose de 200 microgramas $/ \mathrm{kg}$, VO, numa única aplicação (SLATTER, 1990). WHITLEY et al. (1993) recomenda uma segunda aplicação de ivermectina após 6 semanas.

\section{Ativadores de plasminogênio tecidual (APT).}

A aplicação de 25 a 100 microgramas de APT na câmara anterior em casos de hifema, hipópio ou ambos, melhora a transparência do humor aquoso pela retração do tamanho do coágulo (BROOKS, 1992; SPIESS, 1997).

\section{Imunossupressores}

WHITLEY et al. (1993) referem que drogas imunossupressoras tais como a ciclofosfamida ou o clorambucil podem ser usadas no controle de uveítes severas e refratárias ao uso de corticóides sistêmicos.

\section{Vacinação}

ROBERTS (1969) relata que não mais foram observados casos de URE após o uso de bacterinas contra Leptospira aplicadas, anualmente, em rebanhos de animais nos quais foi registrada a ocorrência de uveíte associada a altos títulos sorológicos para Leptospira, sorotipo pomona. Por outro lado, KERN (1987) reporta a possibilidade de exacerbação de casos de uveíte, relacionados à Leptospira, após a vacinação, sugerindo cautela quando da realização dessa prática. Em face dos resultados confli- tantes, como os mencionados, além de observações clínicas, estudos controlados devem ser conduzidos no sentido de se estabelecer o real papel da vacinação na prevenção e controle de novos casos de URE relacionados à leptospirose.

\section{Cirurgia}

A intervenção cirúrgica em casos de uveíte crônica, recorrente e intratável, causadora de dor freqüente, glaucoma secundário e phthisis bulbi deve ser considerada e se baseia na enucleação com ou sem implante de prótese de silicone (KERN, 1987; GLAZE, 1990). SPIESS (1997) refere que resultados promissores têm sido obtidos nos últimos anos mediante a realização de vitrectomias em eqüinos portadores de URE. O objetivo da técnica baseia-se na remoção do exsudato inflamatório e mediadores químicos responsáveis pela manutenção da inflamação intra-ocular.

\section{Manejo de animais não apresentando dor ocular}

Nenhum tratamento é preconizado para olhos portadores de lesões crônicas de uveíte não apresentando sinais de dor (GLAZE, 1990). Alguns animais necessitam de terapia com antiinflamatórios não esteróides em baixas doses, por tempo prolongado, para manutenção da função e conforto ocular (KERN, 1987).

A probabilidade de conservação da visão está relacionada à frequiência e severidade dos episódios recorrentes e ao sucesso do tratamento. Enquanto casos de uveíte relacionados a trauma não perfurante ou úlceras corneanas superficiais, quando tratados adequadamente, apresentam um bom prognóstico quanto à preservação da visão, casos de uveíte recorrente com seqüelas inflamatórias e tratados de forma não eficaz, são de prognóstico reservado quanto à capacidade visual (DAVIDSON, 1992). Os proprietários devem sempre ser comunicados de que se trata de uma enfermidade ocular grave, de difícil controle, freqüentemente dispendiosa, podendo produzir diferentes graus de cegueira.

Não existem meios que possam, objetivamente, predizer a probabilidade de recorrência da uveíte. Assim, quanto maior a severidade dos fenômenos inflamatórios e quanto maior o número de recorrências, mais desfavorável se torna o prognóstico, ou seja, menor é a probabilidade de conservação da visão.

\section{CONCLUSÃO}

Considerando que inúmeras questões relativas à etiologia e à fisiopatologia da URE ainda são desconhecidas, e que a progressão da doença pode comprometer severamente a capacidade funci- 
onal do paciente, através dos diferentes graus de deficiência visual estabelecidos, o reconhecimento precoce das alterações oculares, associado ao tratamento sintomático realizado de forma agressiva e persistente são, até o presente, as principais formas de combate à doença. Infelizmente, o que se observa com freqüência na prática clínica é que muitos animais são encaminhados para avaliação médica nas fases tardias da doença, ou quando já receberam alguma forma de tratamento julgado ineficiente pelo proprietário. Notadamente, nessas circunstâncias, a possibilidade de se evitar a ocorrência de seqüelas oculares responsáveis pelo comprometimento da visão, quando já não existentes, torna-se muito mais difícil, mesmo com a terapia mais adequada. Para tanto, é de extrema importância que os proprietários sejam esclarecidos de forma clara e objetiva quanto às reais chances de recuperação do paciente e estimativas de custo do tratamento. $\mathrm{O}$ acompanhamento clínico do paciente através da realização de exames periódicos permitirá o reconhecimento, não só da eficácia ou ineficiência do tratamento, como também de alterações previamente inexistentes.

\section{REFERÊNCIAS BIBLIOGRÁFICAS}

ABRAMS, K.L., BROOKS, D.E. Equine recurrent uveitis: Current concepts in diagnosis and treatment. Equine Pract, v.12, p.27-35, 1990 .

BEECH, J. Oftalmite recorrente. In: CICLO INTERNACIONAL DE CLÍNICA VETERINÁRIA EQÜINA, 5, 1987, São Paulo. Anais... São Paulo: Jockey Club de São Paulo, 1987. p.198-202.

BROOKS, D.E. Uveitis. In: AUER, J.A. Equine surgery. Philadelphia : Saunders, 1992. p.670-671.

DAVIDSON, M.G. Equine ophthalmology. In: GELATT, K.N Veterinary ophthalmology. $2^{\text {nd }}$ ed. Pennsylvania : Lea \& Febiger, 1991. p.576-610.

DAVIDSON, M. Anterior uveitis. In: ROBINSON, N.E. Current therapy in equine medicine. $3^{\text {rd }}$ ed. Philadelphia : Saunders, 1992. p.592-594.

GLAZE, M.B. Ocular therapeutic techniques. In: ROBINSON, N.E. Current therapy in equine medicine. $2^{\text {nd }}$ ed Philadelphia : Saunders, 1987. p.436-439.

GLAZE, M.B. Equine recurrent uveitis (ERU, Periodic ophthalmia, Moon blindness). In: SMITH,B.P. Large animal internal medicine. St.Louis : Mosby, 1990. p.1239-1243.

HINES, M.T. Immunologically mediated ocular disease in the horse. Vet Clin North Am: Large Animal Pract, v.6, p.501$512,1984$.

JONES, T.C. The relation of brucellosis to periodic ophthalmia in equidae. Am J Vet Res, v.1, p.54-57, 1940.

JONES, T.C. Equine periodic ophthalmia. Am J Vet Res, v.3, p.45-71, 1942.

JONES, T.C., MAUER, F.D., ROBY, T.O. The role of nutrition in equine periodic ophthalmia. Am J Vet Res, v.6, p.67-80, 1945 .
JONES, T.C. Riboflavin and the control of equine periodic ophthalmia. J Am Vet Med Assoc, v.114, p.326-329, 1949.

KERN, T.J. Intraocular inflammation. In: ROBINSON, N.E Current therapy in equine medicine. $2^{\text {nd }}$ ed. Philadelphia : Saunders, 1987. p.445-450.

LAVACH, J.D. Large animal ophthalmology. St.Louis Mosby, 1990. Chap 7: Pupil, iris and ciliary body: p.162-172.

MOORE, C.P. Corneal ulceration. In: ROBINSON, N.E. Current therapy in equine medicine. $3^{\text {rd }}$ ed. Philadelphia : Saunders, 1992. p.596-599.

MAIR, T.S., CRISPIN, S.M. Immunological mechanisms in uveitis. Equine Vet J, v.21, p.391-393, 1989.

MAXWELL, S.A, HURT, D., BRINGHTMAN, A H. et al. Humoral responses to retinal proteins in horses with recurrent uveitis. Prog Vet Comp Ophthal. v.1, p.155-161, 1991.

MILLER, T.R., WHITLEY, R.D. Uveitis in horses. Mod Vet Pract. v.6, p.351-357, 1987 .

O'CONNOR, G.R. Factors related to the initiation and recurrence of uveitis. Am J Ophthal., v.96, p.577-599, 1983.

REBHUN, W.C. Diagnosis and treatment of equine uveitis. J Am Vet Med Assoc, v.175, p.803-808, 1979.

REBHUN, W.C. Diseases of the ocular system. In: COLAHAN, P.T. et al. Equine medicine and surgery. $4^{\text {th }}$ ed. Goleta : American Veterinary Publications, 1991. p.1120-1124.

ROBERTS, S.R. Fundus lesions in equine periodic ophthalmia. J Am Vet Med Assoc, v.141, p.229-239, 1962.

ROBERTS, S.R. Etiology of equine periodic ophthalmia. Am J Ophthal, v.55, p.1049-1055, 1963.

ROBERTS, S.J. Comments on equine leptospirosis. J Am Vet Med Assoc, v.155, p.443-445, 1969.

ROBERTS, S.R. Chorioretinitis in a band of horses. J Am Vet Med Assoc, v.158, p.2043-2046, 1971.

SCHLOTTHAUER, C.F. Recurrent ophthalmia. North Am Vet, v.14, p.18-29, 1933

SEVERIN, G.A Veterinary ophthalmology notes. $2^{\text {nd }} \mathrm{ed}$. Fort Colins : Colorado State University, 1976. Chap. 12: Anterior uvea: p.219-220

SLATTER, D. Fundamentals of veterinary ophthalmology $2^{\text {nd }}$ ed. Philadelphia : Saunders, 1990. Chap. 12: Uvea: p.304-337.

SPIESS, B.M. Equine recurrent uveitis. In: ROBINSON, N.E. Current therapy in equine medicine. $4^{\text {th }}$ ed. Phildelphia : Saunders, 1997. p.363-366.

STANNARD, A.A., CELLO, R.M. Onchocerca cervicalis infection in horses from the western united states. Am J Vet Res, v.36., p.1029-1031, 1975.

WHITLEY, R.D., MILLER, T.R., WILSON, J.H. Therapeutic considerations for equine recurrent uveitis. Equine Pract, v.15, p.16-23, 1993.

YAGER, R.H., GOCHENOUR, W.S., WETMORE, P.W. Recurrent iridocyclitis (periodic ophthalmia) of horses. J Am Vet Med Assoc, v.117, p.207-209, 1950. 